\title{
Philosophy among Astrologers
}

\section{Joanna Komorowska}

\begin{abstract}
Two major astrological works that survive from the second century CE, Claudius Ptolemy's Tetrabiblos and Vettius Valens' Anthologiae, display certain notable differences of approach and conceptual framework. These differences may serve as the starting point for any inquiry concerning both the contemporary mentality and fundamental assumptions which shaped the development and transmission of astrology in the relevant period.
\end{abstract}

\section{Introduction}

It seems obvious that ancient astrologers, by the very fact of their moving around in the cultural milieu of the Roman empire, would at least be acquainted with philosophical issues current in the contemporary world. Yet, did they display an active interest in philosophical matters? If yes, to what extent? What, if any, was the focus of this interest? How did they reconcile the relatively strict demands of contemporary philosophical methodology with what Roger Beck calls, rather tersely, an excess of explanations? ${ }^{1}$ To answer all these questions would demand a massive and extended study far exceeding the limitations of this paper. What we may, however, endeavour to do is a short and rather general inquiry into what may be termed the penetration of philosophical concepts into the astrological writings of the second century $\mathrm{CE}$, an enquiry particularly interesting because of the fortunate coincidence that allows us a glimpse of no less than two astrological minds at work.

Two things need to be clarified at this point. First, the second century issue: the choice of the period is dictated by the simple fact that two major astrological works produced in this period survive till the present day. These are Ptolemy's Tetrabiblos and Vettius Valens' Anthologiae, each of them manifesting a different mindset and different theoretical

\footnotetext{
${ }^{1}$ The remark appears repeatedly in his recent work, A Brief History of Ancient Astrology (Oxford, 2007).
}

Joanna Komorowska, 'Philosophy among Astrologers', Culture And Cosmos, Vol. 11 no 1 and 2, Spring/Summer and Autumn/Winter 2007 pp. 69-86. www.CultureAndCosmos.com 
70 Philosophy among Astrologers

preoccupations at play in their composition. Second, given the variety and the scope of second-century philosophical debates, I assume that at least some ideas, duly reproduced by the not necessarily surviving doxographers, were current among the more educated strata of the Mediterranean poleis, penetrating into more general consciousness, and necessarily influencing the way in which the world was perceived or, indeed, described. ${ }^{2}$ The simplifying accounts contained in the writings of Aëtius, Pseudo-Galen and other authors assembled in Diels' massive Doxographi Graeci, as well as the incoherences of Alcinous' account, may be invoked to testify that a deep and coherent understanding of Platonic or Stoic doctrine was hardly de rigueur even among selfproclaimed intellectuals, while the accessible writings of the kind exemplified by Didascalicus or De Platone would in all likelihood facilitate the incorporation of certain terms and notions into a general conceptual framework of the period, facilitating their penetration into the intellectual discourse of the time. ${ }^{3}$

At this point it seems reasonable to turn our attention to the themes that dominated the philosophical map of the second century - after all, these will most likely resurface in contemporary astrological writings, the writings that form our chief point of interest in this essay. As for metaphysics, the discussion turns around the nature and ontological status of the maker of the world, or around the very question of this latter's generation. ${ }^{4}$ While the ontological question as such is of no immediate

${ }^{2}$ At this point one may invoke an illuminating remark formulated with respect to Ptolemy by Long: 'Ptolemy and his contemporaries were writing for audiences who had been similarly educated to themselves, and whom they could expect to be familiar with an intellectual tradition characterised by a community of concepts, standard questions and answers, common argumentative methods and objections...' (A. Long, 'Ptolemy On the Criterion: An Epistemology for the Practising Scientist', in The Criterion of Truth. Essays written in honour of $G$. Kerferd, eds P. Huby, G. Neal [Liverpool, 1989], p. 151).

${ }^{3}$ H. Diels (Berlin, 1879); it is important to note that at the turn of the last century the underlying pattern of his Doxographi was challenged in the comprehensive study of J. Mansfeld and D. Runia, Aëtiana. The Method and Intellectual Context of a Doxographer (Leiden, 1997). The inconsistencies of Alcinous' Didascalicus were extensively studied by T. Göransson in Albinus, Alcinous, Arius Didymus (Acta Universitatis Gothoburgensis, Studia Graeca et Latina Gothoburgensia LX, Göteborg, 1995).

${ }^{4}$ The issue is related to the potential agreement between the works of Plato and those fathered by his great disciple, Aristotle, which is discussed in G.

Culture and Cosmos 
importance for our writers, some of its implications may bear on their understanding of the world-structure and hence, influence the understanding of nature (phusis), its position and function, the construction of the concept of necessity and, finally, the understanding of the nature of celestial bodies. A side issue of contemporary metaphysics is the question of intermediate beings such as demons - an issue we will encounter again, as the demons will figure prominently in the account of human life presented by Valens. The questions concern also the debate over the issue of fate and providence: the status and the activity of fate, as well as the existence and nature of providential care for the world are avidly debated in the second century, a fact well attested owing to the survival of several important treatises devoted to these problems alone. ${ }^{5}$

Then, there is ethics - the contemporary debates, just as it was before, focus on the character of the summum bonum, the definition and the acquisition of virtues, including axiological debates, and touch on the major issue of human freedom of will. The principal aim of ethics is to establish the guidelines of a happy life, the ultimate goal being always defined as eudaimonia: thus, it concerns itself with what accounts for human happiness, whether it can be achieved and how we can reach it (if at all). Closely connected to the question of primary versus secondary goods, and thus deeply entrenched in ethical discourses, is the issue of oikeiosis - the concept is hardly new, as it formed the basis of the ethical doctrine developed by Antiochus of Ascalon, ${ }^{6}$ yet its prominence in second-century ethics is attested by both Epictetus and Marcus Aurelius. ${ }^{7}$

Furnishing a coherent and workable explanation of the origins of human societies, the idea, albeit of Stoic origin, had penetrated into Platonic thought, thus achieving considerable popularity far beyond radical Stoic circles. The concept, particularly in its social dimensions, is

Karamanolis' comprehensive work, Plato and Aristotle in Agreement? Platonists on Aristotle from Antiochus to Porphyry (Oxford, 2006).

${ }^{5}$ Cf. De fato attributed to Plutarch, as well as Alexander's treatises De fato and De providentia (the latter survives in an Arabic translation only).

${ }^{6}$ See J. Dillon, The Middle Platonists 80 B.C. to A.D. 220 (Ithaca, 1997), p. 78.

${ }^{7}$ The concept of oikeiosis, bearing heavily on the development of Stoic ethical and political philosophy, is not a matter to be discussed in a mere two sentences, so I refer the reader to the exhausive study of T. Engberg-Pedersen, The Stoic Theory of Oikeiosis (Aarhus, 1990), or to a shorter, yet instructive account in T. Brennan's The Stoic Life (Oxford, 2005), p. 154ff. 
72 Philosophy among Astrologers

relatively complex, yet the basics, as explained in the seminal study of Pembroke, ${ }^{8}$ are relatively easy to understand: in our life, we tend to care for those nearest and dearest, which is easily explained by their immediate closeness to us - after all, we share in the same blood; yet, gaining in wisdom, we recognize the common element in others as well, thereby incorporating them into the extended oikos circle. Ideally, this recognition of the common element should lead to the recognition of the unity of humankind, an ideal manifested by Aurelius' Meditations and embraced in Epictetus' Diatribes.

Finally (ironically, one may note that the order employed herewith inverts the Stoic classification of philosophy), what needs to concern us here is the methodological question, dating back to the postulates formulated by Plato in the Socratic dialogues. ${ }^{9}$ This issue reflects upon the possible status of astrology as a science or an art and comprises all attempts to answer the following questions: what is astrology? what is its status? is astrological cognition possible? is it of use and what are its benefits, if any? One may frown upon these questions, considering them at best trivial, yet the establishment of the subject and of the aim intrinsic to a given science is considered of fundamental importance as early as the writings of Plato (e.g. in Charmides or Gorgias), while methodological reflection can boast a tradition reaching back to the Corpus Hippocraticum. ${ }^{10}$ Moreover, it hardly needs emphasizing that the issue was further complicated by the popularity and influence of Aristotle's logical works, a fact confirmed by the works of Galen and by the interesting testimony of Eusebius, who mentions a particular kind of heresy that stemmed from overindulgence in Aristotelian methodology. ${ }^{11}$ After all, the explanatory character of science constitutes a major

\footnotetext{
${ }^{8}$ S. G. Pembroke, 'Oikeiōsis', in Problems in Stoicism, ed. A. A. Long (London, 1971) [hereafter Pembroke, 'Oikeiōsis'], pp. 114-149.

${ }^{9}$ See A. M. Smith 'Knowledge and Expertise in the Early Platonic Dialogues', Archiv für Geschichte der Philosophie (1998), vol. 80, pp. 120-161.

${ }^{10}$ On this latter issue see, e.g., G. E. R. Lloyd 'Techniques and Dialectic: Methods in Greek and Chinese Mathematics and Medicine', in Method in Ancient Philosophy, ed. J. Gentzler (Oxford, 1998), pp. 351-376.

${ }^{11}$ Cf. Praeparatio Evangelica, 813d-814d.
} 
postulate of the Posterior Analytics, and its validity was confirmed by Theophrastus' and Galen's works. ${ }^{12}$

This is a very rough sketch of second-century philosophy, yet it is intended to do no more than indicate the points of possible importance for further discussion: to provide a credible image of what was happening in this interesting epoch, one may better refer to the works of John Dillon, John Whittaker, Jaap Mansfeld or David Runia. ${ }^{13}$ Our case is with astrological writers - the above serves only to emphasise the issues prominent in contemporary discourse. Further on, I shall concentrate on the issue of whether or how the terms charged with philosophical meaning would be employed in the astrological works of the period and whether the study of their use might serve to further our knowledge concerning the two second-century authors.

\section{Astrology and method}

Let us, once again inverting the sequence, begin with methodological issues. In his Tetrabiblos, a work dated to the middle of the second century CE, Claudius Ptolemy will attempt a major re-formulation of astrology, a reconstruction intended, at least according to Fazzo, ${ }^{14}$ to answer the Carneadean criticism of astrology, but also, a far more thrilling possibility, to establish astrology as a science in its own right, i.e. to locate it with reference to the Aristotelian paradigm of demonstrative - and true - sciences. It is important to remember that for Ptolemy, astrology is a sister branch of what we know as mathematical astronomy: in the opening passages of the Tetrabiblos (I 1, 1-3) he openly alludes to astronomical certitude and astronomy's ability to

\footnotetext{
${ }^{12}$ Concerning this, see M. Burnyeat, 'Aristotle on Understanding Knowledge', in Aristotle on Science: The Posterior Analytics, Proceedings of the Eighth Symposium Aristotelicum held in Padua from September 7 to 15, 1978, ed. E. Berti (Padua, 1981) [hereafter Burnyeat, 'Aristotle'], pp. 97-139; K. Ierodiakonou 'Alexander of Aphrodisias on Medicine as a Stochastic Art', in Ancient Medicine in its Socio-Cultural Context; Papers Read at the Congress Held at the Leiden University 13-15 April 1992, Vol. II, Clio Medica 28, eds Ph. J. van der Eijk, H. F. J. Horstmanshoff, P. H. Schrijvers (Amsterdam - Atlanta, 1995), pp. 475-85.

${ }^{13}$ Apart from those already invoked (i.e. the Middle Platonists or the Aëtiana), one may mention e.g. J. Mansfeld's Prolegomena (Leiden, 1994).

${ }^{14}$ S. Fazzo 'Un arte inconfutabile: la difesa dell' astrologia nella Tetrabiblos di Tolomeo', Rivista critica di storia della filosofia (1991), vol. 46, pp. 213-44.
}

Culture and Cosmos 
74 Philosophy among Astrologers

establish what is unchangeable and stable (i.e. the calculable principles of astral motion). While this latter discipline deals with the previsions concerning the future positions and movements of celestial bodies, astrology focuses on their inevitable consequences or, to put it more clearly, with the changes those positions provoke within the sublunary world. ${ }^{15}$ Hence, it operates with methods parallel to those of its more autonomous twin (which, quite appropriately, remains far less involved with the material aspect of reality, and hence far closer to what always is and, more importantly, far closer to the unchangeable and eternal): prognostication relies on general principles that ultimately derive from observation, but is impeded by the interference of the accidental, this latter being a characteristic feature of the sublunary world. Characteristically, one may also note that these principles, at which we arrive by simple observation, are well entrenched in the Greek intellectual tradition - so well entrenched, in fact, that they may easily be converted into something akin to commonplaces (or, to put it more precisely, into something Ptolemy makes sound like commonplaces). ${ }^{16}$ Thus, he argues his point in the following steps:

i. the obvious influence that the Sun exercises on the sublunary world as conceived on most elemental level of the opposition of hot and cold, dry and moist, ${ }^{17}$

\footnotetext{
${ }^{15}$ If we allow for possible Platonic influence, an option strenously opposed by Franz Boll (Studien über Claudius Ptolemäus: ein Beitrag zur Geschichte der griechischen Philosophie und Astrologie [Leipzig, 1894]), but perhaps worthy of consideration in light of the prominent position of the cosmological principles espoused in the Timaeus in contemporary philosophical discourse, we may wonder whether this concept of stars/heaven influencing and shaping terrestrial events would not be linked with the hierarchical arrangement of the universe so prominent in the period (see S. Gersh, Middle Platonism and Neoplatonism: the Latin Tradition [Notre Dame, IN, 1986], pp. 227ff.).

${ }^{16}$ One may note the stress all the commentators of Ptolemy place on his employment of manifest phenomena; cf., e.g. R. Hankinson Cause and Explanation in Ancient Greek Thought (Oxford, 1998) [hereafter Hankinson, Cause and Explanation], p. 370.

${ }^{17}$ Apotelesmatica I, 2.2; the following characteristics are stressed within the influence of the Sun: it is universal, and extends throughout the sublunary world

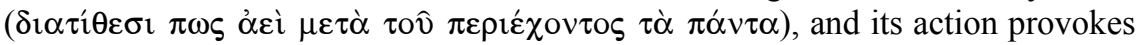

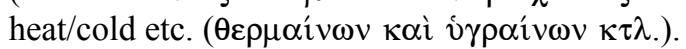

Culture and Cosmos 
ii. the lunar influence on the level of tides and on the growth of plants and animals, ${ }^{18}$

iii. the appearance of certain fixed stars as foreshadowing the appearance of corresponding meteorological phenomena, ${ }^{19}$

iv. the prevalence of solar and lunar influences. ${ }^{20}$

v. Given all these, one must also assume a heavenly influence as well on the germination and maturation of the seed. ${ }^{21}$

Clearly, his aim is to make the last assumption into a self-manifesting truth, a commonplace of human wisdom. To achieve this, he invokes the

\footnotetext{
${ }^{18}$ The influence of the Moon is clearly connected to water levels (one may well remember that it was considered that blood levels increase during the full moon, Manuelis Comnenis ad Glycam ep., CCAG 5/1); a straightforward prohibition against cutting the part of the body that would be assigned to the sign in which the Moon was found at the time of the intervention may be linked to a similar

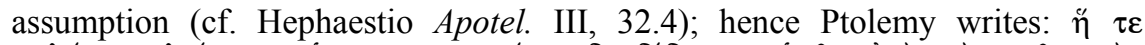

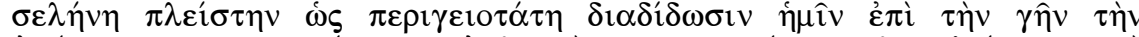

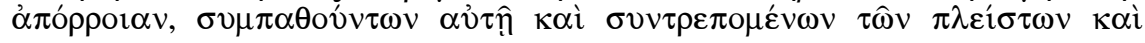

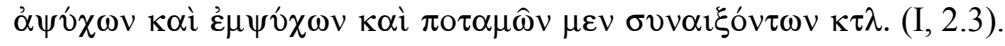

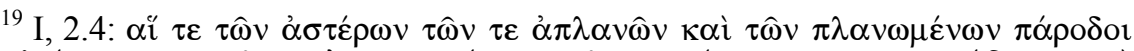

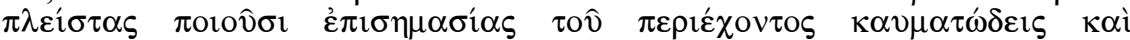

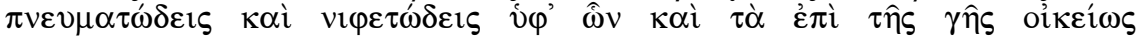
$\delta ı \alpha \tau i \theta \varepsilon \tau \alpha$. F. E. Robbins (Ptolemy Tetrabiblos (Loeb Classical Library, Cambridge, MA/London, 1940, repr. 1994]) [hereafter Robbins] translates (pp. 7, 9): 'Moreover the passages of the fixed stars and the planets often signify hot, windy, and snowy conditions of the air, and mundane things are affected accordingly.'

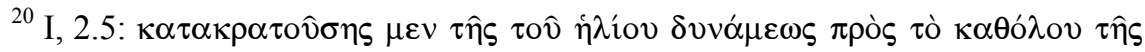

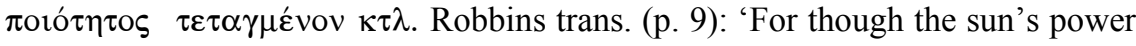
prevails in the general ordering of quality' etc.

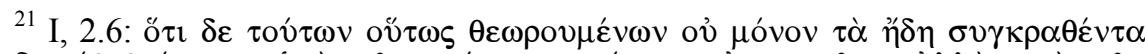

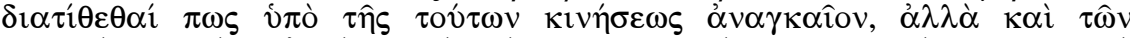

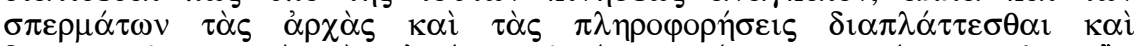

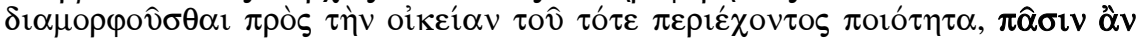

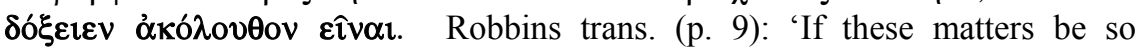
regarded, all would judge it to follow that not only must things already compounded be affected in some way by the motions of these heavenly bodies, but likewise the germination and fruition of the seed must be moulded and conformed to the quality proper to the heavens at the time.'

Culture and Cosmos 
76 Philosophy among Astrologers

authority of unlearned people, who, untrained as they are, prove capable of foreseeing the forthcoming changes in the environment.

What one must note, however, is that in vivid contrast to its twin, astrology has at its disposal an open, incomplete set of data: while the foreknowledge of further stellar position relies on the fundamental and philosophically grounded assumption of the unchangeability of the celestial movements, observational effort cannot furnish humankind with the complete, exhausive data pool that would list effects that all possible stellar combinations have on matter. Consequently, while the overall guidelines derive from past observation and from the 'discovery' of certain permanent features that may be traced to each celestial object, the individual thema is always a product of conjecture. Such an attitude and such an emphasis on the incompleteness, on the openness of the data pool brings astrology close to medicine, an approximation Ptolemy was in all likelihood not only aware of, but even actively sought to create. ${ }^{22}$ (He actually does compare astrologers with physicians at I, 3.) After all, only a few would deny the scientific character of medical lore, even in spite of its all too obvious imperfections or, for that matter, in spite of the raging strife dividing its practitioners.

A short note must be made at this point: it seems justified that Ptolemy's approach to astrology was necessarily influenced by the attitude he assumes toward mathematical astronomy. The introduction to his Syntaxis, frequently perceived as an elaboration of Aristotle's division of sciences in Metaphysics E, may also be perceived as an encomium for mathematics, the mightiest and best kind of science available to a human being. This, as Liba Taub has persuasively argued, ${ }^{23}$ is not necessarily an Aristotelian, but very much a Platonic element, sending us back to the cosmology of the Timaeus and to the idea that the contemplation of regularity that remains so manifest in the heavenly motion may be of crucial importance for the remembrance of what truly is. ${ }^{24}$ To quote the crucial passage:

\footnotetext{
${ }^{22}$ For stochasmos as the basis of medical prognosis (and indeed therapy) cf. the aforementioned article of K. Ierodiakonou (see note 12).

${ }^{23}$ In her Ptolemy's Universe: The Natural Philosophical and Ethical Foundations of Ptolemy's Astronomy (Chicago, 1993), pp. 19-38.

${ }^{24}$ Cf. T. K. Johansen, Plato's Natural Philosophy. A Study of the TimaeusCritias (Cambridge, 2004), pp. 160-76. Additionally, Plato is described as being particularly partial to mathemetical sciences by none other than Alexander of Aphrodisias in his Comm. in Metaph. A, p. 52. 10-15 B.
} 
For this is the best science to help theology along its way, since it is the only one which can make a good guess at [the nature of] that activity which is unmoved and separated; [it can do this because] it is familiar with the attributes of those beings which are on the one hand perceptible, moving and being moved, but on the other hand eternal and unchanging, [I mean the attributes] having to do with motions and the arrangement of motions... With regard to virtuous conduct in practical actions and character, this science, above all things, could make men see clearly; from the constancy, order, symmetry and calm which are associated with the divine it makes its followers lovers of this divine beauty, accustoming them and reforming their natures, as it were, to a similar spiritual state. (tr. Toomer I, 1., p. 7 Heiberg) ${ }^{25}$

The precision and stability of mathematics is to be compared favourably to the obscurity of theological research. Indeed, in an important passage Ptolemy claims that the certainty and beauty derived from mathematics remains vastly superior to any theological speculation:

Only mathematics can provide sure and unmistakable knowledge to its devotees, provided one approaches it rigorously. For its kind of proof proceeds by indisputable methods, namely arithmetic and geometry. Hence we were drawn to the investigation of that part of theoretical philosophy, as far as we were able to the whole of it, but especially to the theory concerning divine and heavenly things. For that alone is devoted to the investigation of the eternally unchanging... (tr. Toomer I, 1. p. 7 Heiberg)

Clearly, mathematics is to be preferred to advanced philosophical/ontological speculations. This may (though this must remain uncertain) constitute an allusion to the otherwise fascinating discussions concerning the nature and comprehensibility of the first principle that are

\footnotetext{
${ }^{25}$ Ptolemy's Almagest, trans. and annot. G. J. Toomer (London, 1984) [hereafter Toomer]; Claudii Ptolemaei Opera quae exstant omnia, I Syntaxis mathematica, ed. J. L. Heiberg (2 vols, Leipzig, $1898+1903)$ [hereafter Heiberg].
} 
78 Philosophy among Astrologers

attested for the second century $\mathrm{CE}^{26}$ Indeed, given this rather hostile remark, it is no surprise that the closest Ptolemy comes to metaphysics is his assumption of rational order, an order likely to be related to some rational ruling principle which, however, remains unmentioned in his works. ${ }^{27}$ Yet to keep with the present line of inquiry, one may note that the elevated position of mathematics as the only science which leads us toward knowledge of immaterial eternal being may be regarded as parallel to a view attested in Numenius who, in one of the surviving passages of his work, states with relative clarity that the study of numbers far surpasses any other intellectual activity (fr. 2 des Places) ${ }^{28}$ The extent and potential importance of this latter parallel remains a matter for more extensive study, yet, for the present purposes, it would be useful to note its possibility, or, at the very least, the presence of a concept that might be described as having deeply Platonic resonances.

The uniqueness of Ptolemy's approach stands out in comparison with the attitude represented by Valens: for the latter, as for the Roman poet Manilius or the authors of the Hermetic treatises assembled in the Corpus Hermeticum, astrology is a gift of the divine, a lore whose origins reach far back into the time when humans enjoyed considerable closeness with the gods. ${ }^{29}$ Indeed, for the Antiochene the ultimate sources of the astrological doctrine of epembaseis lie with the divine, due to sudden revelation rather than the careful acquisition of data. ${ }^{30}$ Hence, instead of a

${ }^{26}$ One may remember, e.g. Alcinous, Didasc. X; concerning the discussion, cf.

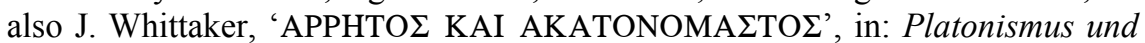
Christentum: Festschrift für Heinrich Dörrie (Jahrbuch für Antike und Christentum, Ergänzungsband 10), eds H.D. Blume and F. Mann (Münster, 1983), pp. 303-306 (= Studies in Platonism and Patristic Thought, London 1984, XII).

27 On this cf., e.g. A. Barker, Scientific Method in Ptolemy's Harmonics (Cambridge, 2000), pp. 28-29.

28 One may note that this continues the Platonic tradition attested also in Alexander, Commentaries on the Metaphysics (in Metaph. A, p. 52. 10-15 B).

${ }^{29}$ Cf. Anthologiae VI, 1 or IV, 11; concerning the possible Hermetic affinities of the idea, the connection to Manilius and other, later, writings, as well as for the possible rhetorical grounds for this idea of divine illumination, see J. Komorowska Vettius Valens of Antioch - an Intellectual Monography (Kraków, 2004) [hereafter Komorowska, Valens], pp. 155-259.

${ }^{30} \mathrm{Cf}$. IV, 11; the motif of revelatory experience is attested in other astrological sources beside Valens, even though they date from a later period. One may, 
causal explanation postulated by the Greek 'scientific' thought, ${ }^{31}$ we are faced with a vastly different kind of justification: the revelatory experience and its contents furnish the ultimate argument in favour of astrology (one may call it a superior authority argument). Not for Valens the long, tedious causal investigations - his lore is grounded in the supreme authority of the divine, remaining therefore exempt from the demands of scientific proof, consistency or, indeed, explanation - nothing could be further from the rigidity of apodeixis postulated by Aristotle or, to avoid the extreme position, that demanded by the 'usual' scientific procedures. Such a grounding of its principles presents us with a vastly different picture of astrology than that encountered (indeed, construed) by Ptolemy: instead of the stochastic art parallel to medicine, we are faced with a product of superior intelligence, which eludes any claims Aristotelian logic could possibly make. Yet, simultaneously, the notion of revelation in itself seems to be a Pandora's box, leading to the inevitable question of universal order as presented in the works of Valens.

\section{The image of the world}

Now, the image of the universe that may be inferred from the works of Valens is a matter of considerable embarrassment: like the structure and formal features of his Anthologiae, the picture which emerges may appear disjointed and full of intrinsic contradictions. Yet when studied, Valens's views may be shown to display astonishing similarities with the doctrines current in the period, attesting to his awareness of contemporary philosophical debates.

Let us start where I began: with the quasi-epistemological issue of the origin of astrology as a divinatory science. First, the possiblility of foreknowledge stems from the providential design of the divine. When considering the matter in VII, 4.1 Valens duly notes:

however, mention the fact that the origins of astrobotany will be later linked to the revelation of Asclepius (to Thessalus of Thralles, the founder of the methodical sect of medicine, better known as the principal victim of Galen's ridicule in de methodo medendi $\mathrm{I}$ ); on the prominence of the motif in astrological literature see Komorowska, Valens, pp. 248-59.

${ }^{31}$ Scientific in the Aristotelian sense, hence ultimately reliant on the principles explored in the Posterior Analytics; on the importance of causal explanation in the Greek concept of knowledge see Hankinson, Cause and Explanation, pp. 125-59; Burnyeat, 'Aristotle'. 
80 Philosophy among Astrologers

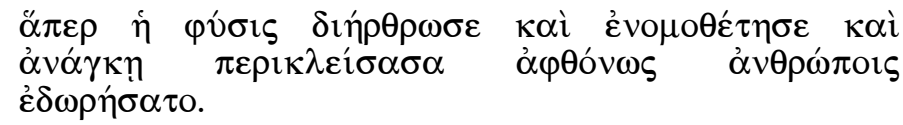

...what nature articulated and ordained by law and, confining by necessity, presented ungrudgingly to men. ${ }^{32}$

This is hardly a philosophically original statement. Yet one has to keep in mind its consequences: nature appears here as a law-giver, law-keeper and law-revealer. It is interesting to note that the divinatory context may suggest the Stoic or Stoicizing source of the idea, an impression that may be reinforced once we recall that Valens expressly links the possibility of foreknowledge to the divine decree, which aimed at providing a human being with the means to achieve ethical virtues:

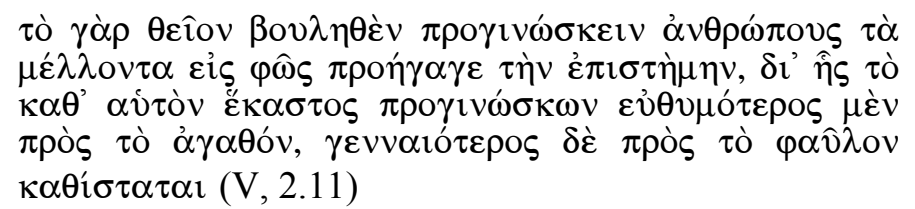

For the divine, which wished men to foreknow the future, has brought to light the knowledge through which each one who knows in advance about what concerns him becomes more cheerful about the good, and more nobly resigned to the bad.

However, the image resulting from the above passages may well be inspired by Platonic thought, particularly by the consideration concerning the nature and working of the world-soul, the nature of which was widely debated in the period, and by the close link the Platonists maintained between destiny and law, ${ }^{33}$ the connection relying on Plato's own allegations in the Timaeus, where the Demiurge reveals 'nomoi heimarmenoi' to the assembled (and created) souls. ${ }^{34}$ The appearance of

\footnotetext{
${ }^{32}$ English translations from Valens provided by Dorian Greenbaum, to whom I extend sincere thanks.

33 Thus, e.g. Pseudo-Plutarch, De Fato 569d-570b.

${ }^{34}$ Cf. Tim. 41e. One may remember that the Timaeus, and particularly the account of the creation of soul, was the object of intensive study during the
} 
Ananke, necessity, and the suggestion of the circular movement it enforces may also be suggestive of a Timaean origin for the idea: it seems symptomatic that the description of the World Soul's emergence (which was identified with phusis as the organizing power of the universe) is described by the doxography-derived work of Alcinous as a process of ordering, of the divine exerting its influence to bring the world-soul to appropriate circular motion (Didascalicus XIV, 169). A similar emphasis on the ordering of the disorderly pre-cosmic soul appears also in Plutarch's De animae procreatione $1116 \mathrm{a}-\mathrm{c} .{ }^{35}$

There is another, possibly more promising, indication that a Platonizing influence may stand behind Valens' view of the universe. When describing the way in which Nature (phusis) relates to the soul, the Antiochene notes:

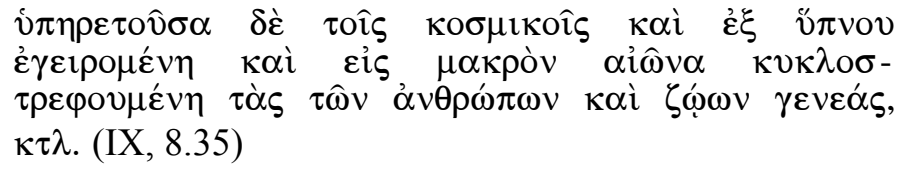

submitting to the cosmic [laws], and waking from sleep and in a great year turning cyclicly the races of men and animals, etc.

The notion of the great year is known from both Plato and the Stoics, where it was linked with the ekpurosis doctrine. ${ }^{36}$ Yet it may also be related to the predestination theories attested in the second century CE. Interestingly, Pseudo-Plutarch's De fato makes an express claim that on the return of a great year everything will happen again just as it happens now. ${ }^{37}$

At the same time, there is something familiar about the sleep passage. Possibly the most famous employment of this particular motif is in

Middle Platonic era, a fact witnessed, e.g. by its prominence in Plutarch's Quaestiones Platonicae (five of the ten essays concern the dialogue).

${ }^{35}$ Here is no place to discuss the concept of soul-generation/awakening in the Middle Platonic thought: on the subject see J. Dillon, The Middle Platonists (London, 1977, rev. 1996) and others.

${ }^{36}$ Cf. most recently R. Salles, 'Determinism and Recurrence in Early Stoic Thought' Oxford Studies in Ancient Philosophy (2003), vol. 24, pp. 253-72.

${ }^{37}$ De fato 569 a-c. 
Republic X, 621b, where souls about to be incarnated fall asleep so as to be awakened in their new bodies. Yet there are other parallels that may confirm that something of Plato's idea survives in the passage. In the already quoted work of Alcinous, the Demiurge awakens the World Soul from a deathlike slumber (karos). ${ }^{38}$ Moreover, in describing the activity and movement of Nature, Valens' passage seems to reinforce the idea that it is something of an active entity parallel to the Timaean World Soul, the force actually governing the universe, dominant in the world in accordance with the preset decree. All order, all proportion proceeds from Nature as constrained by law - this is the picture we obtain from the cosmological passages of the Anthologiae.

One may claim, however, and quite rightly so, that it is the doctrine of predestination that remains of fundamental importance when considering Valens' views. Now, this is a problem even more complex than the cosmological account. Clearly, should we consider Anthologiae V, 2 alone, the resulting image would probably be identifiable as compatible with the radical version of simplistic Stoicism, where a well-meaning, yet universe-oriented fate leaves man no choice except for possible dissent: yet, simultaneously, this very dissent is a major transgression, the source of all possible suffering (interestingly, this is a view of Stoicism that would dominate anti-Stoic polemics such as Alexander's: the immutable decree of fate, a man standing before a choice that is not really a choice, etc.). Yet, should we risk reading further, we would inevitably come to a point where this simple outlook would prove at best insufficient. The ideal of a stratiotes tes heimarmenes (soldier of fate), so convincingly drawn in $\mathrm{V}, 2$, is hard to reconcile with the far more pessimistic picture of a patient slave, forced to bear with his master's whims, as painted in IX, 12.19:

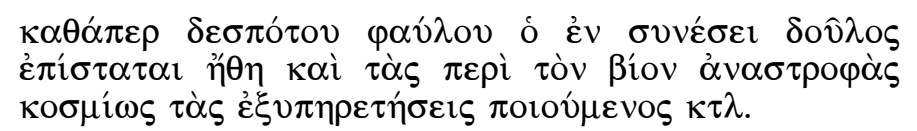

But just as a slave who in his intelligence knows the habits of a bad master and makes provisions regularly for these behaviours in daily life etc.

As if this were not complicated enough, we face a further challenge: some humans, due to their ethical excellence, enjoy particular closeness

${ }^{38}$ Didasc. XIV 169. 
with daimones that are charged with providential care of the individual. These entities are by no means Valens' invention: the opinion that the world is full of daemonic beings is attested for Heraclitus and daemons are charged with the care of the human soul in its incarnated existence in Plato's Republic 617d-e. Additionally, should we consider the example of Plutarch or Apuleius, demonology seems to be much in vogue in the second century CE. ${ }^{39}$ Yet, it may well be symptomatic that the demons charged with caring for an individual may prove in turn beneficial (such seems to be the demon of Achilles, Odysseus and, hardly surprisingly, of Valens himself) or malefic. The circumstances of the latter occurrence are particularly striking: for those who rebel against the order of the universe, the demon becomes a bane, forcing them ineluctably toward punishment and disaster (one example is that of the biaiothanatos of II, 41.90-93, the other of a villain depicted in VI, 9.10-11). The notion, one may note, is beautifully echoed in the Corpus Hermeticum, where we read that the evil are harassed by tormentors destined to bring them to a bitter end:

As for those without Nous, the evil, the worthless, the envious, the greedy, murderers, the ungodly, I am very far from them, having given way to the avenging spirit, who assaults each of them through the senses, throwing fiery darts at them. He also moves them to greater acts of lawlessness so that such a man suffers greater retribution etc. $(\mathrm{CH} \text { I } 23)^{40}$

Now, the parallels between Valens' work and the Corpus are a matter vast enough to occupy us for far more than the allotted space allows. Still, it may be useful to remember, for example, that considerable conceptual similarities occur between Valens' concept of divine revelation and the image of divinity revealing itself in $\mathrm{CH}$ I (the Poimandres treatise). ${ }^{41}$ Also, Valens' demon seems to be particularly interested in an individual's welfare, acting as a counsellor even in divinatory matters (IX, 12.7; 19).

\footnotetext{
${ }^{39}$ Concerning the contemporary fascination with the demonic, cf. E. R. Dodds, Pagan and Christian in an Age of Anxiety (Cambridge, 1965), pp. 37-68, or F. E. Brenk, 'Demonology in the Early Imperial Period', Aufstieg und Niedergang der römischen Welt (Berlin, 1986), II, 16.3, pp. 2068-2145.

${ }^{40}$ Translation from C. Salman, D. van Oyen, W. D. Wharton and J. P. Mahé, The Way of Hermes (Rochester, VT, 2000).

${ }^{41}$ See Komorowska, Valens, pp. 160-69 et al.
} 
84 Philosophy among Astrologers

This would present us with a picture of a demon far more helpful than that of Plato's Socrates, yet a picture not without parallels in the Platonist literature of the period (one may invoke Apuleius' De deo Socratis XVI, 156).

Now, how do we reconcile the providential care of the demon, the supreme governance of Necessity, the working of Nature that provides us with access to the universal law and, finally, the notion of fate pressing us down as if we were mere slaves instead of most noble soldiers in the service of the divine order? A possible solution may be offered by the hierarchical arrangement of the universe and its agencies, an arrangement we encounter in the contemporary treatises of Pseudo-Plutarch and Apuleius: three levels of fate, three levels of providence. ${ }^{42}$ The Law is in the movement of the universe, i.e. it is related to the World Soul; meanwhile, the individual fates are in the charge of demons, who may either guide us toward a better understanding of the whole, or oppress us in our vices. Thus, having differing levels of fate, we may differentiate between those who serve the world-related one, and those who are oppressed by the changeability of individual fortune. The evil, capricious master is in all likelihood the individual fate.

The time has come to leave the Antiochene aside and return to his Alexandrian near contemporary. Certainly, there are few traces of metaphysical concerns in Ptolemy's Apotelesmatica. Preceded by the Syntaxis, the work relies on the arguments made for the sphericity of the Earth without any explicit allusion. The explanation of the divinatory power of astrology relies on physics and observation rather than elaborate theories concerning the status and function of Nature. The stars influence the world owing to their physical activity, via the elemental power they exercise. The very nature of the proof for astrology's validity is indicative of the gap separating Ptolemy from Valens, as no mention of divinely preordained law, no mention of the agencies that actually govern the universe emerge in the former: the celestial bodies act according to their nature, exercising a purely elemental influence on the sublunary world. Clearly, this is not to say that the two are mutually exclusive, yet it is symptomatic that there is no mention of demons, no discussion of the status of fate: the presentation relies on sensible data rather than advanced ontological theory. Strikingly, to argue in favour of the correspondence between the sublunary and the celestial, Ptolemy will reach into the domain of ethics and proceed to argue in terms of oikeiosis and oikeiotes

${ }^{42}$ See respectively De fato 572f-574a, De Platone XII 205. 
as well as their cognates. These will be particularly prominent in Book Two, ${ }^{43}$ where the concept of sunoikeiosis is clearly employed to advance the notion of terrestrial regions being particularly affiliated to certain sections of heaven. It is there that we witness Ptolemy's particular skill as he makes the term which is charged with a particular meaning in philosophy work for his concept of physical affinity, stressing the intrinsic, deeper implications of the ethical notion, emphasising the concept of affinity as similarity. ${ }^{44}$

Indeed, it is in the ethical discussions that the two authors come closest, unanimously regarding foreknowledge as beneficial to humankind. For Ptolemy, the equanimity that results from this foreknowledge is essential in the achievement of happiness, for in recognizing the course of events that stems from the stellar configurations we are able to recognize the inevitability of change, while the understanding of its causes necessarily prevents us from any overly emotional response to a sudden evil. Should we add that mathematics (and thereby mathematical astronomy) is the only way to understand the immaterial and changeless, we are faced with a recipe for the attainment of a perfectly balanced theoretical and practical life. In the area of theory, we study mathematics; in practice, we are supported by our theoretical knowledge when unraveling, even through conjecture (stochasmos) (which in fact is the only way in which the changeable may be reckoned), the mysteries of future events, thereby preparing ourselves for the change about to come. The two are in fact necessarily bound together, and it is no wonder that the author of the Apotelesmatica makes so clear a statement about the nature of astrology as related to mathematical astronomy: the latter deals with the changelessness, the former with the material aspect of the world.

\section{Conclusions}

One may claim, and quite rightly, that this is hardly an exhaustive discussion of the issues intrinsic in the employment of philosophical doctrines of the era in astrological writings. Yet it seems, to some extent, representative of our two authors. The approach of Valens, imbued with notions such as revelation, divinely ordained teachings, etc., complicated by apparent inconsistencies and culminating in a typically Stoic notion

\footnotetext{
${ }^{43}$ Tetr. II, 3 remains particularly instructive in this respect.

${ }^{44}$ For the complexity of the term oikeiosis see Pembroke, 'Oikeiōsis'.
} 
86 Philosophy among Astrologers

that virtue (manifest in the acceptance of the divine decree) is a sufficient provision for happiness - for it is in recognizing the divine pattern that we achieve the necessary means for a virtuous life - remains a result of superficial reading that renders the author unable to provide a clear and coherent picture of his métier. As a result, the theoretical passages of his work tend toward what might be called by a prejudiced reader a pseudophilosophizing babble, where the major point of interest can be briefly described as 'Where did he get this particular idea?'

On the other side of the barricade stands Ptolemy. Should we accept the fact that, while mathematical astronomy, so comprehensively described in the Syntaxis, is the study of eternal, unchangeable yet material reality in its stable, unchanging aspect (after all, Ptolemy is occasionally charged with having deliberately suppressed all mention of precession), the physical reality of the opening books of the Apotelesmatica deals with the effects that eternal, continuously and unchangeably moving matter produces in the phenomenal, sensible, and fluctuant world. One work deals with heaven as ordered in the Timaeus, the other with reality troubled by accident, and with a subject affected by both the limitations of hule and the limited nature of human knowledge. The two, it seems, supplement each other in a sense much more profound than just being a description of two methods of the same science. In short, what I suggest is that Ptolemy was deeply aware of the importance of his claim: one of his methods gives us an insight into the nature of eternal being, the other allows us to live in a world that is subject to change, accident and disorder. In practicing one, we look toward the eternal and noetic; in practicing the other, we look onto sensible reality.

When comparing the way the authors relate to contemporary philosphical discourse, one may well be struck by the active interest displayed by Ptolemy, who seems to be consciously employing the terms taken from this discourse to employ them in changed circumstances, thus changing and manipulating their meaning (as he also manipulates astrological dogmas). His use of language is shaped by the primary telos, by his desire to present us with 'scientific' astrology - in short, he seems to manipulate at the level of language almost as much as he does on the level of dogma. By contrast, Valens seems to incorporate philosophical concepts as he understands them, even if the level of his understanding of the inherent complexities remains - owing to our fragmentary knowledge of his cosmological views - hard to gauge. 